Jurnal Ilmu Komunikasi UHO : Jurnal Penelitian Kajian Ilmu Komunikasi dan Informasi.

Volume 6, No. 4, Oktober 2021, hlm 405-416

\title{
KONVERGENSI MEDIA PADA RADIO KOTA FM (88.1 FM) SEBAGAI RADIO DANGDUT DI KOTA SURABAYA
}

\author{
Dina Anik Rahayu ${ }^{1}$, Diana Amalia ${ }^{2}$ \\ Program Studi Ilmu Komunikasi Fakultas Ilmu Sosial dan Ilmu Politik Universitas \\ Pembangunan Nasional "Veteran" Jawa Timur \\ Jalan Raya Rungkut Madya Gunung Anyar, Surabaya, Indonesia
}

\begin{abstract}
ABSTRAK
Saat ini media massa sangat berkembang pesat dalam kehidupan manusia akibat adanya perkembangan teknologi digital. Berbagai jenis media terus bermunculan. Bentuk media massa saat ini banyak yang melakukan kolaborasi dengan berbagai bentuk media baru dengan menerapkan konvergensi media. Radio Kota FM Surabaya merupakan salah satu media yang melakukan konvergensi media guna dalam upaya mempertahankan keberadaannya dikalangan masyarakat. Hal inidapat dilihat bahwa Radio Kota FM Surabaya dalam era konvergensi media saat ini juga telah memiliki jumlah pendengar yang lebih banyak jika dibandingkan dengan radio lainnya dalam satu jarigan Mercury Media Group, dengan memanfaatkan media baru sebagai sarana dalam meningkatkan jumlah audiencenya. Tujuan dari penelitian ini yaitu untuk mengetahui dan menjelaskan terkait model konvergensi media pada Radio Kota FM Surabaya sebagai radio dangdut di Kota Surabaya. Studi ini menggunakan metode penelitian deskriptif kualitatif. Teori yang digunakan dalam penelitian ini yaitu teori konvergensi yang dikemukakan oleh Grant. Hasil penelitian ini menunjukkan bahwa pada konvergensi newsroom dilakukan dengan para jurnalis bersatu di ruang produksi dengan tetap menjalankan tugas sesuai dengan platform masing-masing. Kemudian pada konvergensi newsgathering dilakukan training dan penambahan sumber daya manusia guna menunjang dilakukan konvergensi. Selanjutnya pada konvergensi content dilakukan dengan mengkombinasikan media yang ada mulai dari foto dan video diawali poster, teaser video, reminder, dan podcast.
\end{abstract}

Kata-kata Kunci: Konvergensi Media; Radio; Kota FM Surabaya 


\title{
MEDIA CONVERGENCE ON CITY FM RADIO (88.1 FM) AS DANGDUT RADIO IN SURABAYA CITY
}

\begin{abstract}
Currently the mass media is growing rapidly in human life due to the development of digital technology. Various types of media continue to emerge. Many forms of mass media currently collaborate with various forms of new media using media convergence. Radio Kota FM Surabaya is one of the media that performs media convergence in an effort to maintain its existence among the public. It can be seen that Radio City FM Surabaya in the current era of media convergence also has more listeners than other radios in the Mercury Media Group network, by utilizing new media as a means of increasing the number of its audience. The purpose of this study is to find out and explain the media convergence model on Radio City FM Surabaya as dangdut radio in the city of Surabaya. This study uses a qualitative descriptive research method. The theory used in this study is the theory of convergence proposed by Grant. The results of this study indicate that the newsroom convergence is carried out with journalists united in the production room while still doing their respective tasks. Then at the newsgathering convergence, training and additional human resources are carried out to support the convergence. Furthermore, content convergence is carried out by combining existing media ranging from photos and videos beginning with posters, video teasers, reminders, and podcasts.
\end{abstract}

Keywords: Media Convergence; Radio; City FM Surabaya 
Jurnal Ilmu Komunikasi UHO : Jurnal Penelitian Kajian Ilmu Komunikasi dan Informasi.

Volume 6, No. 4, Oktober 2021, hlm 405-416

\section{PENDAHULUAN}

Saat ini media massa sangat berkembang pesat dalam kehidupan manusia. Media massa memenuhi keseharian hidup masyarakat yang tanpa disadari juga mempengaruhi kehidupan manusia itu sendiri sehingga segala sesuatu yang dilakukan oleh manusia berkaitan dengan media. Seiring dengan perkembangan zaman dan kemajuan teknologi, masyarakat mendapatkan informasi tidak hanya berasal dari media cetak seperti surat kabar dan majalah, melainkan informasi juga bisa didapatkan melalui media digital akibat era digitalisasi. Saat ini perkembangan teknologi dalam hal komunikasi telah merubah sistem komunikasi dari analog menjadi komunikasi ke arah digital. Kinerja sistem digital tentunya lebih baik daripada sistem analog. Dalam melakukan penyesuaian terhadap teknologi yang ada, Indonesia mengawalinya dengan teknologi transmisi gelombang radio analog dan sentral analog. Kemudian dalam perkembangan berikutnya mulai diterapkan teknologi digital dan transmisi satelit (Munandar \& Soedjarwo, 2018 dalam Sari, 2020). Sehingga penggunaan teknologi digital mampu memberikan dampak yang efektif bagi masyarakat serta memunculkan berbagai jenis media.

Oetomo (2002) dalam Lahyanto (2018) berpendapat bahwa internet merupakan singkatan dari international network yang didefinisikan sebagai jaringan komputer yang besar. Dimana jaringan tersebut terdiri dari beberapa jaringan-jaringan kecil yang saling terhubung satu sama lain. Kemudian Allan (2005) dalam Lahyanto (2018) juga berpendapat bahwa internet merupakan sekumpulan jaringan komputer yang saling terhubung satu sama lain secara fisik dan memiliki kemampuan untuk membaca dan menguraikan berbagai protokol komunikasi tertentu. Sehingga dari pengertian diatas dapat diketahui bahwa internet merupakan sekumpulan jaringan satu dengan jaringan lain yang saling terhubung yang memiliki kemampuan untuk membaca berbagai protokol komunikasi tertentu.

Saat ini berbagai jenis media masih terus bermunculan, berkembang seiring dengan perkembangan teknologi. Bentuk media massa saat ini banyak yang melakukan kolaborasi dengan berbagai bentuk media baru (new media). Meskipun demikian berbagai bentuk media baru yang telah terpengaruh kecanggihan internet tersebut tidak berarti mematikan semua bisnis media massa konvensional seperti radio, televisi dan surat kabar. Bahkan hal itu membuat industri konvensional mulai berbenah untuk menarik perhatian dan mendekatkan audien agar tetap memilih media tersebut sebagai sarana informasi ataupun hiburan dengan menyesuaikan terhadap perkembangan teknologi internet (Anggraini, 2018). Seperti halnya dalam industri penyiaran radio yang masih tetap eksis hingga saat ini. 
Jurnal Ilmu Komunikasi UHO : Jurnal Penelitian Kajian Ilmu Komunikasi dan Informasi.

Volume 6, No. 4, Oktober 2021, hlm 405-416

Jika dibandingkan dengan media lainnya di zaman modern ini radio memiliki kekurangan. Radio merupakan media massa yang sifatnya auditori, dalam artian bentuk dari output siaran radio adalah berupa suara yang didengarkan massa. Isi pesan yang disiarkan radio cenderung mudah hilang dari ingatan pendengar karena tidak dapat diulang untuk dimainkan kembali di waktu yang berbeda. Sehingga pesan radio bersifat sekilas, tidak terperinci, dan tidak detail (Asy'ari dan Luthfi, 2018). Asy'ari dan Luthfi (2018) lebih lanjut lagi juga menjelaskan bahwa radio memiliki kelemahan lain berupa banyaknya gangguan yang bersifat teknis, yang biasa disebut mechanic noise factor. Mengingat bahwa unsur utama siaran radio adalah berupa suara atau bunyi untuk didengarkan, maka adanya kelemahan tersebut menjadi faktor yang sangat berdampak pada kondisi dapat didengarkan atau tidaknya serta kejernihan siaran radio itu sendiri. Sedangkan pada media lain, faktor tersebut cenderung berada pada tingkat yang minimal, sehingga radio juga mulai ditinggalkan audience karena dianggap terlalu banyak kekurangan dan tidak lagi memiliki sisi yang menggiurkan. Hanya saja saat ini tren untuk akses informasi ataupun untuk berkomunikasi telah berubah. Munculnya media baru justru semakin menajamkan sisi keunikan media yang lainya.

Berdasarkan data terkait media habit yang dipaparkan Nielsen dalam Asy'ari dan Luthfi (2018) disebutkan bahwa tren pendengar radio terus mengalami penurunan tiap tahunnya. Bahkan pada Tahun 2015, angka pendengar radio secara global hanya mencapai $15,77 \%$. Penurunan tersebut berbanding terbalik dengan kondisi pendengar atau audience situs internet yang jumlahnya mengalami peningkatan tiap tahunnya, termasuk pada Tahun 2015 yang jumlahnya adalah mencapai $37,845 \%$ atau lebih dari 2 kali lipat audience radio. Sedangkan data terbaru terkait pendengar radio di Indonesia pada Tahun 2018 didasarkan pada hasil survei indikator sosial budaya Badan Pusat Statistik dalam Kusnandar (2019), hanya terdapat sekitar $13,31 \%$ masyarakat berusia 10 tahun ke atas yang masih mendengarkan radio. Angka tersebut mengalami kemerosotan cukup banyak dibandingkan Tahun 2003 yang masih berada pada Angka 50,29\%. Karenanya, saat ini radio pun turut berbaur dengan media baru untuk mengikuti perkembangan zaman sekaligus sebagai upaya dalam meningkatkan kembali eksistensinya. Berbauranya berbagai radio yang merupakan media konvensional tersebut dalam satu perangkat elektronik dengan memanfaatkan bantuan internet guna mempermudah masyarakat dalam menemukan informasi. Berdasarkan hal tersebut maka banyak instansi radio yang masih bertahan untuk berusaha beradaptasi terhadap perubahan teknologi dengan melakukan konvergensi media. Lister et al. dalam 
Jurnal Ilmu Komunikasi UHO : Jurnal Penelitian Kajian Ilmu Komunikasi dan Informasi.

Volume 6, No. 4, Oktober 2021, hlm 405-416

McEwan (2010) berpendapat bahwa konvergensi media merupakan kata kunci yang menggambarkan penyatuan teknologi yang sebelumnya tidak terkait. Hal tersebut didukung dengan pernyataan Kalamar (2016) bahwa konvergensi dapat diartikan dalam beberapa hal meliputi: 1) merupakan sinonim konsolidasi media, yang mewakili deskripsi ketika suatu media atau perangkat memiliki fungsi baru yang dapat melakukan tugas yang mana pada awalnya ada dua atau lebih perangkat yang dibutuhkan untuk melakukan tugas tersebut; 2) dapat disinonimkan sebagai webvergence atas adanya praktik penggunaan internet sebagai media penyampai berita pada berbagai pers dan organisasi penyiaran; 3) konvergensi dianggap sebagai proses pengkaburan batas media dalam komunikasi dari titik ke titik, sehingga media lebih sering tidak memiliki batasan yang jelas.

Konvergensi media yang dilakukan oleh radio menyebabkan radio yang sebelumnya menggunakan gelombang radio dengan transmisi sinyal analog menjadi penggunaan medium streaming berupa gelombang yang kontiniu dan mentransmisikan gelombang suara melalui internet. Sistem kerja tersebut memungkinkan radio bisa menyiarkan acaranya secara lebih luas ke seluruh dunia, dengan syarat bahwa pendengar harus memiliki perangkat dan jaringan internet. Sehingga, konvergensi media pada dasarnya selain berguna dalam mempermudah pengguna (masyarakat) dalam mengakses informasi secara lebih efisien, juga berguna bagi penyiaran untuk memperluas jaringan dan wilayah siaran, terlebih lagi bagi radio yang merupakan media massa dengan frekuensi pendek. Berbagai manfaat dan efisiensi yang ditawarkan tersebut kemudian menjadi peluang menggiurkan bagi radio untuk melakukan konvergensi media, termasuk salah satunya adalah yang dilakukan Radio Kota FM Surabaya (88.1 FM).

Grant (2009) berpendapat bahwa konvergensi media terdiri atas tiga bentuk sebagai berikut: Pertama, Konvergensi newsroom dimana pada jenis konvergensi ini, seorang jurnalis media massa pada suatu platform yang berbeda, misalnya surat kabar, online, dan televisi, menyatukan dirinya dalam satu ruang produksi berita. Jurnalis mengerjakan tugas sesuai dengan platform medianya. Kedua, konvergensi newsgathering dimana pada jenis konvergensi ini, jurnalis dituntut untuk mencapai suatu tingkatan multitasking. Dengan melalui suatu pelatihan, jurnalis diharuskan mampu untuk melakukan pekerjaan yang dilakukan oleh media dengan platform lain dalam satu grup. Misalnya adalah seorang wartawan cetak yang juga harus mampu membuat berita untuk cetak, online, sekaligus televisi. Lebih lanjut lagi, biasanya wartawan juga diharuskan mampu mengambil foto atau video yang dijadikan sebagai bahan berita. Ketiga, konvergensi content dimana pada 
Jurnal Ilmu Komunikasi UHO : Jurnal Penelitian Kajian Ilmu Komunikasi dan Informasi.

Volume 6, No. 4, Oktober 2021, hlm 405-416

konvergensi jenis ini berfokus pada penyampaian isi media yang berbentuk multimedia, dengan menggabungkan antara teks, gambar, video, suara, website, dan lainnya.

Radio Kota FM Surabaya (88.1 FM) atau yang selanjutnya dalam penelitian ini disebut sebagai Radio Kota FM merupakan radio yang berada di bawah naungan manajemen PT Radio Kota Buaya Mandiri yang merupakan bagian dari Mercury Media Groups. Radio Kota FM telah mengudara sekitar 21 tahun di Kota Surabaya yang dalam hal musik, genre utama yang disiarkan Radio Kota FM adalah dangdut, baik dangdut populer, koplo, nostalgia, new entry maupun lainnya. Dangdut sebagai tipe musik utama Radio Kota FM juga ditegaskan pada tagline Radio Kota FM yakni "Dangdutnya Surabaya", meskipun pada kegiatan operasionalnya, target pendengar bukan hanya pada Kota Surabaya melainkan pada jangkauan yang lebih luas termasuk luar negeri. Radio Kota FM dalam era konvergensi media saat ini juga telah memiliki jumlah pendengar yang lebih banyak jika dibandingkan dengan radio lainnya dalam satu jarigan Mercury Media Group, dengan memanfaatkan internet sebagai sarana dalam meningkatkan jumlah audiencenya, termasuk dengan melakukan siaran pada aplikasi streaming yang bisa didengar dan diputar kapan pun, dalam jangkauan yang lebih luas, serta secara lebih efisien.

Konvergensi media yang dilakukan pada Radio Kota FM pada dasarnya juga perlu dipahami bahwa tidak hanya berbentuk penyatuan media radio dengan media baru, melainkan juga dalam penerapan manajemen dan pengelolaan media akan terdapat perubahan yang signifikan. Bagaimana publikasi dilaksanakan oleh pengelola radio akan berbeda pada era new media. Jika pada masa sebelum konvergensi media interaksi antata penyiar radio dengan audience dilakukan melalui telefon interaktif, maka setelah adanya konvergensi media interaksi juga bisa dilakukan dengan memanfaatkan media sosial yang dianggap lebih efisien (Trinoviana, 2017). Karenanya, penggabungan antara Radio Kota FM dengan media lainnya secara garis besar melingkupi perubahan yang terjadi secara menyeluruh dan kompleks.

Terlebih lagi diungkapkan oleh Negroponte dalam Trinoviana (2017) bahwa dalam teori konvergensi, kombinasi antara industri media tradisional dengan industri terkomputerisasi akan menciptakan tipe komunikasi baru. Setiap industri media memiliki celah perbedaan yang semakin sempit yang menyebabkan masing-masing media memiliki posisi yang sama untuk mengambil keuntungan dan menarik audiens. Sehingga selain berpengaruh terhadap media massanya, era konvergensi media juga berimplikasi pada proses bisnis dan industri medianya (Negroponte dalam Trinoviana, 2017). 
Jurnal Ilmu Komunikasi UHO : Jurnal Penelitian Kajian Ilmu Komunikasi dan Informasi.

Volume 6, No. 4, Oktober 2021, hlm 405-416

Berdasarkan penelitian yang telah dilakukan sebelumnya oleh Prihartono (2016) dengan judul "Surat Kabar dan Konvergensi Media (Studi Deskriptif Kualitatif Model Konvergensi Media Pada Solopos)" menjelaskan bahwa konvergensi media yang dilakukan Solopos merupakan jawaban atas tuntutan industri media bahwa surat kabar harus mempersiapkan platform digital untuk menghadapi media digital yang terus tumbuh dan model konvergensi yang dilakukan adalah model konvergensi newsgathering dimana dalam model ini seorang jurnalis dituntut untuk mampu mencapai tingkatan multitasking yaitu satu reporter bekerja untuk beberapa media atau beberapa platform dalam satu grup. Penelitian tersebut menggunakan konsep model konvegensi media yang dikemukakan oleh Grant (2009). Jika dibandingkan dengan penelitian yang dilakukan saat ini maka perbedaan terletak pada lokasi penelitian, dimana lokasi penelitian yang dilakukan oleh Prihartono (2016) terletak pada Media Solopos. Sedangkan penelitian saat ini dilakukan di Radio Kota FM (881) Surabaya. Perbedaan lain juga terletak pada objek penelitian, dimana penelitian yang dilakukan oleh Prihartono (2016) berkaitan dengan media cetak sedangkan pada penelitian ini objek penelitiannya merupakan media elektronik yakni radio.

Kemudian penelitian lain juga dilakukan oleh Trinoviana (2017) dengan judul "Strategi Konvergensi Radio sebagai Upaya Perluasan Pasar Audience dan Iklan (Studi Kasus pada Swaragama FM (101.7 FM), Geronimo FM (106.1 FM), dan Prambors Radio (102.2 FM/ 95.8 FM)" menjelaskan bahwa konvergensi media yang menjadi perhatiannya taitu bentuk konvergensi media, strategi yang dilakukan dalam memperluas audience dan jangkauan pemasang iklan, faktor penghambat dan pendukung radio dalam perluasan pasar audience dan jangkauan pemasang iklan, serta bagaimana dampak dari konvergensi media dalam perluasan pasar audience dan jangkauan pemasang iklan, serta adanya hasil yang diperoleh radio setelah melakukan perluasan pasar audience dan jangkauan pemasang iklan. Konvergensi media yang dilakukan radio melalui media daring seperti web streaming dan media sosial telah mempengaruhi radio dari segi pendengar dan pemasangan iklan. Penelitian tersebut menggunakan konsep untuk mengungkap fenomena konvergensi media dari segi ekonomi adalah perluasan pasar audience atau captive market. Jika dibandingkan dengan penelitian yang dilakukan saat ini maka perbedaan terletak pada lokasi penelitian, dimana lokasi penelitian yang dilakukan oleh Trinoviana (2017) terletak pada Swaragama FM (101.7 FM), Geronimo FM (106.1 FM), dan Prambors Radio (102.2 FM/ 95.8 FM. Sedangkan penelitian saat ini dilakukan di Radio Kota FM (881) Surabaya. Perbedaan lain juga terletak pada konsep analisis konvergensi media, dimana penelitian yang 
Jurnal Ilmu Komunikasi UHO : Jurnal Penelitian Kajian Ilmu Komunikasi dan Informasi.

Volume 6, No. 4, Oktober 2021, hlm 405-416

dilakukan oleh Trinoviana (2017) menggunakan konsep untuk mengungkap fenomena konvergensi media dari segi ekonomi adalah perluasan pasar audience atau captive market. Sedangkan pada penelitian ini menggunakan teori model konvergensi media yang dikemukakan oleh Grant (2009)

Berdasarkan uraian tersebut tujuan dari penelitian ini yaitu untuk mengetahui dan menjelaskan terkait model konvergensi pada Radio Kota FM Surabaya (88.1 FM) sebagai radio dangdut di Kota Surabaya.

\section{METODE PENELITIAN}

Penelitian ini ditujukan untuk menjelaskan terkait model konvergensi media pada Radio Kota FM Surabaya (88.1 FM) sekaligus menguraikan perubahan yang terjadi. Informasi yang diungkap dalam penelitian ini berupa pendeskripsian, penjabaran, atau penggambaran terkait objek penelitian dan fenomena yang diteliti. Karenanya, jenis penelitian yang dipilih adalah penelitian deskriptif kualitatif karena didasarkan pada berbagai fakta yang ditemukan di lapangan dan sumber data lainnya. Unit analisis dalam penelitian ini adalah pihak-pihak yang berkaitan secara langsung dengan pengelolaan dan manajemen penyiaran Radio Kota FM, seperti General Manager, Program Director, Head Production, serta Social Media Writer, dan pendengar Radio Kota FM Surabaya.

Sumber data penelitian ini yaitu data primer yang berasal dari informan secara langsung dan data sekunder dari penelitian ini adalah berasal dari studi literatur yang diperoleh dari buku, jurnal, maupun artikel internet. Selain itu dokumen yang didapat dari Radio Kota FM meliputi profil perusahaan, struktur organisasi, dan lainnya juga merupakan bagian dari data sekunder penelitian. Kemudian teknik pengumpulan data yang digunakan dalam penelitian ini yaitu wawancara, observasi, dokumentasi serta studi literatur. Selanjutnya teknik analisis data yang digunakan dalam penelitian ini yaitu teknik analisis data model interaksi yang dikemukakan oleh Miles dan Huberman. Miles dan Huberman dalam Nugrahani (2014) menjelaskan bahwa metode analisis data kualitatif menggunakan model interaksi terdiri dari empat kegiatan yaitu pengumpulan data, reduksi data, penyajian data, serta penarikan kesimpulan dan verifikasi

\section{HASIL DAN PEMBAHASAN}

Hasil wawancara berupa informasi yang diperoleh dari informan sesuai dengan perspekif dan pengalaman yang dimiliki oleh informan yang bersangkutan. Saat proses analisis 
Jurnal Ilmu Komunikasi UHO : Jurnal Penelitian Kajian Ilmu Komunikasi dan Informasi.

Volume 6, No. 4, Oktober 2021, hlm 405-416

dikaitkan hasil wawancara dengan beberapa teori-teori yang ada untuk menjawab rumusan masalah pada penelitian ini. Kemudian hasil dari wawancara aka dikelompokkan menjadi beberapa kategori terkait dengan konvergensi media yang dilakukan oleh Radio Kota FM Surabaya. Peneliti melakukan pengelompokkan jawaban yang telah diperoleh dari informan ke dalam teori konvergensi media untuk mengetahui dan menjelaskan terkait model konvergensi pada Radio Kota FM Surabaya (88.1 FM) sebagai radio dangdut di Kota Surabaya sekaligus menguraikan perubahan yang terjadi atas konvergensi tersebut. Grant (2009) berpendapat bahwa terdapat tiga bentuk yang dilakukan dalam konvergensi media yaitu konvergensi newsroom, konvergensi newsgathering, dan konvergensi content.

Pertama, konvergensi newsroom. Pada bentuk konvergensi ini, peneliti menemukan bahwa terjadi perbedaan dalam produksi program yang ada di Radio Kota FM Surabaya. Sebelum dilakukannya konvergensi media, produksi program yang ada di Radio Kota FM Surabaya hanya berfokus pada persiapan setiap akan dilakukan on air saja. Namun setelah dilakukannya konvergensi media, produksi program yang ada di Radio Kota FM Surabaya terdapat program on air, online, dan off air. Sehingga program yang ditawarkan kepada masyarakat semakin beragam dengan memanfaatkan berbagai platform media seperti aplikasi streaming Onears, sosial media seperti instagram (@kotafm881), twitter (@kotafm881), facebook (Kota FM Surabaya), youtube (Kota FM 881), dan website (kotafmsurabaya.id). Kemudian dalam proses pembuatan program dilakukan bersamaan dalam ruang kantor Radio Kota FM Surabaya namun tetap sesuai dengan tugas pokok dan fungsi masing-masing. Setidaknya terdapat minimal satu konten yang harus di upload pada setiap platform media digital yang dimiliki oleh Radio Kota FM Surabaya. Sehingga menuntut para pengelola platform media untuk lebih kreatif dan inovatif dalam proses pembuatan konten yang ada sesuai dengan pertimbangan yang telah dilakukan. Proses produksi program diatas telah sesuai dengan pendapat yang dikemukakan oleh Grant (2009) bahwa para jurnalis bersatu dalam ruang produksi program, namun tetap mengerjakan tugas sesuai dengan pertimbangan produksi program platform medianya masing-masing.

Kedua, konvergensi newsgathering. Bentuk ini berkaitan dengan pengadaan suatu pelatihan atau training khusus serta dilakukan evaluasi kerja secara kontinyu yang diupayakan oleh suatu industri media agar jurnalis atau sumber daya manusianya dapat mencapai tingkatan multitasking (Grant, 2009). Pendapat tersebut telah sesuai dengan yang dilakukan oleh Radio Kota FM Surabaya. Peneliti menemukan bahwa pelatihan/workshop yang diadakan oleh Radio Kota FM Surabaya dengan mengundang pihak dalam 
Jurnal Ilmu Komunikasi UHO : Jurnal Penelitian Kajian Ilmu Komunikasi dan Informasi.

Volume 6, No. 4, Oktober 2021, hlm 405-416

meningkatkan kompetensi sumberdaya Radio Kota FM Surabaya. Untuk memenuhi tuntutan Radio Kota FM Surabaya menjadi radio yang sudah menerapkan konvergensi media secara rutin upgrate pengetahuan SDM terkai dengan perkembangan digital media meskipun dimasa pandemi mengalami penurunan pendapatan tidak pernah dilakukan pengurangan pegawai. Hal ini disiasati dengan mengubah kegiatan yang awalnya full interaktif dengan penyiar diganti dengan program playlist dan membantu perusahaan untuk menekan biaya produksinya. Penambahan pegawai tersebut dilakukan karena melihat perkembangan teknologi juga semakin pesat menunut kapbilitas sumber daya manusia yang baik dalam memanfaatkan teknologi digital. Selain itu terdapat evaluasi kinerja yang dilakukan oleh Radio Kota FM Surabaya guna memperbaiki setiap kekurangan yang ada di Radio Kota FM Surabaya

Ketiga, konvergensi content. Berkaitan dengan konvergensi content dapat dikatakan bahwa hal tersebut mengarah pada sudut pandang penyampaian suatu konten (Hamida, 2020). Pada bentuk konvergensi ini peneliti menemukan bahwa bentuk penyampaian isi media di Radio Kota FM Surabaya lebih memainkan alur timeline dan memanfaatkan kombinasi media yang ada seperti foto, video, streaming, dan yang lainnya. Diawali dengan upload poster berbentuk foto, kemudian teaser berbentuk videografi dan podcast saat ini yang sedang trend di kalangan masyarakat. Selain itu strategi yang lainnya yaitu mengemas program dengan menggunakan budaya Surabaya tanpa meninggalkan bahasa nasional dan dikemas dengan bentuk lelucon atau parikan sehingga bisa dipahami dan diterima di kalangan masyarakat. Hal tersebut sesuai dalam model teori konvergensi content yang dikemukakan oleh Grant (2009) menyatakan bahwa konvergensi content berfokus pada penyampaian isi media yang berbentuk multimedia dengan menggabungkan antara gambar, teks, video, podcast, website ataupun yang lainnya.

Berdasarkan hasil dan penbahasan diatas, apabila dibandingkan dengan penelitian sebelumnya yang dilakukan oleh Prihartono (2016) dapat diketahui bahwa memiliki hasil konvergensi media yang berbeda. Pada penelitian yang dilakukan oleh Prihartono (2016) diketahui bahwa konvergensi media yang dilakukan oleh Media Solopos hanya menerapkan konvergensi newsgathering. Sedangkan pada hasil penelitian ini diketahui bahwa Radio Kota FM Surabaya menerapkan konvergensi newsroom, konvergensi newsgathering, dan konvergensi content. Kemudian apabilan dibandingkan dengan penelitian yang dilakukan oleh Trinoviana (2017) dapat diketahui bahwa Konvergensi media yang dilakukan oleh Radio Swaragama FM (101.7 FM), Geronimo FM (106.1 FM), dan Prambors Radio (102.2 
Jurnal Ilmu Komunikasi UHO : Jurnal Penelitian Kajian Ilmu Komunikasi dan Informasi.

Volume 6, No. 4, Oktober 2021, hlm 405-416

FM/ 95.8 FM melalui media daring seperti web streaming dan media sosial telah mempengaruhi radio dari segi pendengar dan pemasangan iklan. Sedangkan pada hasil penelitian ini diketahui bahwa Radio Kota FM Surabaya konvergensi media tidak hanya terletak pada media daring saja, melainkan juga terjadi konvergensi pada isi konten/program serta pada sumber daya yang tersedia di Radio Kota FM Surabaya.

\section{SIMPULAN}

Berdasarkan hasil ananlisis yang dilakukan peneliti mengenai "Konvergensi pada Radio Kota FM Surabaya (88.1 FM) Sebagai Radio Dangdut di Kota Surabaya” peneliti menemukan konvergensi media yang dilakukan oleh Radio Kota FM Surabaya yang dapat ditarik kesimpulan. Pertama, pada Radio Kota FM Surabaya konvergensi newsroom dilakukan dilakukan para jurnalis di ruang produksi sesuai dengan tetap menjalankan tugas sesuai dengan platform media digital masing-masing. Kedua, pada konvergensi newsgathering pada Radio Kota FM Surabaya dilakukan dengan peningkatan sumberdaya di bidang digital menyesuaikan dengan perkembangan teknologi yang pesat agar sumberdaya tersebut mampu memanfaatkan teknologi digital serta dilakukan evaluasi secara personal dan general guna menemukan alternatif strategi dalam meningkatkan kinerja sumberdaya kedepannya. Ketiga, konvergensi content yang dilakukan di Radio Kota FM Surabaya dengan upload poster yang disebarkan melalui platform media digital dengan konten berbentuk foto poster, kemudian dilanjutkan dengan upload teaser, dilakukan reminder serta diadakan program podcast dengan memanfaatkan platform media digital yang dimiliki oleh Radio Kota FM Surabaya. 
Jurnal Ilmu Komunikasi UHO : Jurnal Penelitian Kajian Ilmu Komunikasi dan Informasi.

Volume 6, No. 4, Oktober 2021, hlm 405-416

\section{DAFTAR PUSTAKA}

Asy’ari, N. A. S., \& Luthfi, M. (2018). Analisis Penerapan Konvergensi Media pada Usaha Penyiaran Radio di Ponorogo. Jurnal Perspektif Komunikasi, 1(3).

Kalamar, D. (2016). Convergence of Media and Transformation of Audience. Informatologia, 49(3-4), 190-202.

Kusnandar, V. B. (2019). Hanya 13\% Masyarakat yang Masih Mendengarkan Radio. Databoks.

McEwan, R. (2010). Radio: Challenges and New Directions. Communication Journal of New Zealand, 11(1 July), 1-116.

Nugrahani, F. (2014). Metode Penelitian Kualitatif: Dalam Penelitian Pendidikan Bahasa. Solo: Cakra Books.

Prihartono, A. W. (2016). Surat Kabar dan Konvergensi Media (Studi Deskriptif Kualitatif Model Konvergensi Media pada Solopos). Jurnal Channel, 4(1), 105-116.

Trinoviana, A. (2017). Strategi Konvergensi Radio sebagai Upaya Perluasan Pasar Audience dan Iklan (Studi Kasus pada Swaragama Fm (101.7 Fm), Geronimo Fm (106.1 Fm), dan Prambors Radio (102.2 FM/95.8 FM)). Jurnal Komunikasi, 12(1), 35-50. https://doi.org/10.20885/komunikasi.vol12.iss1.art3 